Chronic Obstructive Pulmonary Diseases: Journal of the COPD Foundation

\title{
Comorbidity Distribution, Clinical Expression and Survival in COPD Patients with Different Body Mass Index
}

Miguel J. Divo, MD, ${ }^{1}$ Carlos Cabrera, MD, ${ }^{2}$ Ciro Casanova, MD, ${ }^{3}$ Jose M. Marin, MD, ${ }^{4}$ Victor M. Pinto-Plata, MD, ${ }^{1}$ Juan P. de-Torres, MD, ${ }^{5}$ Javier Zulueta, MD, ${ }^{5}$ Jorge Zagaceta, MD, ${ }^{5}$ Pablo Sanchez -Salcedo, MD, ${ }^{5}$ Juan Berto, MD, ${ }^{5}$ Claudia Cote, MD, ${ }^{6}$ and Bartolome R. Celli, $\mathrm{MD}^{1}$ for the BODE Collaborative Group

\section{Abstract}

Rationale: Contrary to the general population, in patients with chronic obstructive pulmonary disease (COPD) a low body mass index (BMI) is associated with excess mortality, while obesity appears protective (obesity paradox). We hypothesized that BMI is associated with a distinct number and expression of comorbidities in patients with COPD. The type of comorbidity may relate to mortality variability.

Objectives and Methods: We followed 1659 COPD patients for a median of 51 months [IQR 27-77] with detailed comorbidity records and tracking pulmonary function, exercise capacity, dyspnea, health status, and cause of death. The cohort was categorized into the 5 National Heart Lung and Blood Institute (NHLBI) BMI groups with determination made about each group's relationship to specific comorbidities, clinical parameters and risk for death. Results: Whereas osteoporosis, substance abuse, abdominal aortic aneurism and peripheral arterial disease were more prevalent in patients with low BMI, metabolic and cardiac problems were more frequent in those with high BMI. The BMI was inversely related to the ratio of forced expiratory volume in 1 second $\left(F E V_{1}\right)$ to forced vital capacity (FVC)(FEV 1 \%), BODE (Body mass index, airway Obstruction, Dyspnea, Exercise capacity) index and hyperinflation, had a "U" shape with dyspnea and the St. George's Respiratory Questionaire (SGRQ) score and an inverse "U" with exercise capacity. The crude mortality rate was $60 \%, 43 \%, 37 \%, 36 \%$ and $28 \%$ from the lowest to highest BMI groups ( $\mathrm{p}<.0001)$. More respiratory deaths were observed in the lowest BMI group even though they had a lower number of comorbidities.

Conclusions: Different BMI categories are associated with distinct clinical expressions of COPD and comorbidity patterns. The relationship between BMI and mortality in patients with COPD remains an unresolved paradox.

Abbreviations: body mass index, BMI; World Health Organization, WHO; forced expiratory volume in 1 second, FEV $\mathbf{1}_{\mathbf{1}}$; forced vital capacity, FVC; FEV 1 to FVC ratio, FEV $_{\mathbf{1}}$ \%; Body mass index, airway Obstruction, Dyspnea, Exercise capacity scale, BODE index; American Thoracic Society, ATS; European Respiratory Society, ERS; kilogram, kg; National Institutes of Health, NIH; diffusing capacity of the lung for carbon monoxide, DLCO; inspiratory capacity to total lung capacity ratio, IC/TLC; modified Medical Research Council dyspnea scale, mMRC; analysis of variance, ANOVA; confidence interval, CI; National Health and Nutrition Examination Study, NHANES

Funding Support: Institutional support.

Date of Acceptance: July 24, 2014

Citation: Divo MJ, Cabrera C, Casanova C, et al. Comorbidity distribution, clinical expression and survival in COPD patients with different body mass index. J COPD F. 2014; 1(2): 229-238. doi: http://dx.doi.org/10.15326/jcopdf.1.2.2014.0117

\section{This article has an online data supplement}

1 Pulmonary and Critical Care Division, Brigham and Women's Hospital, Harvard Medical School, Boston, MA

2 Pulmonary Department, Hospital Universitario de Gran Canaria Dr Negrin, Las Palmas de Gran Canarias, Spain

3 Pulmonary Department, Hospital Universitario La Candelaria, Universidad de La Laguna, Santa Cruz de Tenerife, Spain
4 Respiratory Service, Hospital Universitario Miguel Servet, Zaragoza, Spain

5 Department of Pulmonology, University Clinic of Navarra, Pamplona, Spain

6 Division of Pulmonary and Critical Care Medicine, the Bay Pines Veterans Affairs Healthcare System, University of South Florida, Tampa 


\section{Address correspondence to:}

Miguel J. Divo, MD

Pulmonary and Critical Division

Brigham and Women's Hospital

75 Francis St., Boston, MA 02115

Email: mdivo@partners.org

(857) 307-0310

\section{Keywords:}

body mass index; BMI; comorbidity; chronic obstructive pulmonary disease; COPD; mortality; obesity paradox

\section{Introduction}

Chronic obstructive pulmonary disease (COPD) is a heterogeneous disease of the lungs with systemic manifestations that affect the phenotypic expression of the disease, its course and outcomes. ${ }^{1-4}$ One of such factors is the body mass index (BMI), a crude yet simple clinical parameter useful to estimate body adiposity. ${ }^{5}$ Use of the BMI is recommended by the National Heart Lung and Blood Institute (NHLBI) ${ }^{6}$ and it has been shown to contribute to the expression of COPD phenotypes ${ }^{7,8}$ through its influence on pulmonary mechanics, ${ }^{9}$ systemic inflammation and its biomarkers, ${ }^{10}$ and ultimately on mortality. ${ }^{1,11}$ However, the association between BMI to specific comorbidities and longitudinal outcomes in patients with COPD has been less well characterized.

We hypothesized that specific comorbidities would cluster across the BMI spectrum and this in turn would influence mortality. In addition, we hypothesized that the BMI would have an effect on the phenotypic manifestation of the disease. To test this hypothesis we explored the prevalence of COPD-related comorbidities in different BMI categories and their possible association with increased risk of death. We also determined the distribution of degree of obstruction, hyperinflation, exercise capacity, dyspnea perception and quality of life by BMI strata in patients with COPD attending pulmonary clinics and enrolled in the BODE (Body mass index, airway Obstruction, Dyspnea, Exercise capacity) cohort.

\section{Methods}

\section{Study Participants}

The BODE registry is an ongoing prospective multicenter cohort study of COPD patients attending outpatient pulmonary clinics at one of the $5 \mathrm{BODE}$ study centers (Tampa, Boston, Pamplona, Tenerife, and Zaragoza). The ethics committee at each of the participating centers approved the study and all patients signed informed consent.

The inclusion and exclusion criteria have been previously described. ${ }^{1}$ In summary, COPD was defined on the basis of a smoking history and lung function testing following the American Thoracic Society (ATS)/European Respiratory Society(ERS) standards. ${ }^{12}$ Patients were excluded if they had an illness other than COPD that was likely to result in death within 6 months or inability to take the lung function and 6-minute walk tests. Between November 1997 and March 2009, 1664 patients were enrolled in the study and followed until either the time of death or until March 2011.

\section{Anthropometrics}

Height was measured in bare or stocking feet and recorded in meters at 2 decimal levels. Weight was measured by calibrated scale in kilograms with participants wearing their normal clothes but without their shoes. To correct for this, a 1 kilogram $(\mathrm{kg})$ of the measured weight was subtracted. BMI is calculated by dividing the subject's weight in kgs by the square of height in meters.

Participants were assigned into one of the categories according to their recruitment BMI as: 1) BMI <21 $\mathrm{kg} / \mathrm{m}^{2}$ (underweight) 2) $21<\mathrm{BMI}<25 \mathrm{~kg} / \mathrm{m}^{2}$ (normal weight) 3) $25 \geq \mathrm{BMI}<30 \mathrm{~kg} / \mathrm{m}^{2}$ (overweight), 4) 30 $\geq \mathrm{BMI}<35 \mathrm{~kg} / \mathrm{m}^{2}$ (obesity type I) and 5 ) BMI $\geq 35 \mathrm{~kg} /$ $\mathrm{m}^{2}$ (obesity type II and III). This stratification is based on the NHLBI classification of overweight and obesity, ${ }^{6}$ modified for the cutoff for the underweight group based on the evidence that in patients with COPD a BMI of $\leq$ $21 \mathrm{~kg} / \mathrm{m}^{2}$ are at increased risk of death. ${ }^{1,13}$ The Obesity Type II and III groups were merged in order to have a meaningful number of participants for the purpose of analysis.

\section{Clinical Variables}

Pulmonary function tests (post-bronchodilator $\mathrm{FEV}_{1} \%$ predicted, $\mathrm{FEV}_{1} / \mathrm{FVC}$, diffusing capacity of the lung for carbon monoxide [DLco] and the inspiratory to total lung capacity ratio [IC/TLC]), and the 6-minute walk test (6MWD) were measured following the ATS/ERS standards. ${ }^{14-16}$ Participants completed the St. George's Respiratory questionnaire (SGRQ) and the modified Medical Research Council dyspnea (mMRC) scale questionnaire.

Comorbidities were systematically recorded through 
direct questioning for the following conditions: 1) Those diseases included in the Charlson Comorbidity Index ${ }^{17}$ (19 comorbidities); 2) All comorbidities listed in the participant's medical record; or 3) Those expressed during enrollment interviews and subsequent visits.

\section{Survival and Cause of Death}

The follow-up time was determined from the date of enrollment to the date of death or last study visit up to March 2011 (right censored). Death or loss to follow-up was verified by calling each participant or their family if they failed to return for appointments, and if we were unable to reach them, by checking the social security death index (United States).

Cause-specific mortality was ascertained by each site investigator to the highest detail possible and then categorized in a systematic and blinded fashion (masked to site, comorbidities and BMI) by 4 of the investigators (BC, CC, JZ and MD) as either death related to 1) respiratory causes including $C O P D, 2)$ cardiovascular diseases, 3) cancer, 4) other causes, or 5) unknown. ${ }^{18}$

\section{Statistical Analysis}

Continuous variables are reported as mean \pm SD or median and 25-75 interquartile range. Comorbidity prevalence and cause-specific death are expressed as proportions. Comparisons between BMI groups were performed using the analysis of variance (ANOVA) test for categorical variables and for continuous variables with normal distribution the Tukey's test or the Dunn's test for non-normal distribution was used. We determined which particular comorbidity(ies) were independently associated with increased risk for death for each BMI category using the Cox proportional hazard model correcting for age, gender, degree of obstruction and cigarette smoking. We collapsed the BMI category $\geq 30$ to $35(n=332)$ and the category $\geq 35 \mathrm{~kg} / \mathrm{m}^{2} \quad(\mathrm{n}=156)$ into 1 category to increase the power of the model. A total of 24 candidate comorbidities were incorporated in the model selected from univariate analysis.

Survival is reported using a Kaplan-Meier survival plot and its significance tested using the log-rank test. The Cox proportional hazard model was used to evaluate the overall and cause-specific mortality risk for each BMI category, corrected for age and $\mathrm{FEV}_{1} \%$ predicted. To estimate the effect in each BMI category, we calculated the risk ratios using patients with BMI $21<\mathrm{BMI}<25 \mathrm{~kg} /$ $\mathrm{m}^{2}$ (normal weight ${ }^{1-4,6}$ ) as the reference group.

A $p$ value of less than 0.05 was considered statistically significant. All analyses were performed using SAS JMP Pro $^{\circledR}$ software, version 11.0 (SAS Institute).

\section{Results}

The baseline characteristics of the 1659 patients included are shown in Table 1 .

\section{Table 1. Participants' Characteristics}

Participants Included in Analysis

\begin{tabular}{|c|c|}
\hline \multicolumn{2}{|l|}{ Demographic } \\
\hline $\mathrm{N}$ & 1659 \\
\hline Age & $66 \pm 9$ \\
\hline Male n $(\%)$ & $1477(89 \%)$ \\
\hline \multicolumn{2}{|l|}{ Spirometry } \\
\hline $\mathrm{FEV}_{1} \%$ & $49 \pm 20$ \\
\hline GOLD I $(\%)$ & $135(8 \%)$ \\
\hline GOLD II $(\%)$ & $593(36 \%)$ \\
\hline GOLD III (\%) & $639(39 \%)$ \\
\hline GOLD IV (\%) & 292 (17\%) \\
\hline \multicolumn{2}{|l|}{ BODE Index } \\
\hline $\mathrm{BODE}($ mean $\pm S D)$ & $3.7 \pm 2.6$ \\
\hline BODE $0,1,2(\%)$ & $595(36 \%)$ \\
\hline BODE 3,4 (\%) & $470(28 \%)$ \\
\hline BODE $5.6(\%)$ & $312(19 \%)$ \\
\hline BODE $7,8,9,10(\%)$ & $282(17 \%)$ \\
\hline \multicolumn{2}{|l|}{ Body Mass Index (BMI) } \\
\hline BMI (mean \pm SD) & $27.02 \pm 5.53$ \\
\hline $\mathrm{BMI} \leq 21 \mathrm{n}(\%)$ & $254(15 \%)$ \\
\hline $\mathrm{BMI}>21-<25 \mathrm{n}(\%)$ & $295(18 \%)$ \\
\hline $\mathrm{BMI} \geq 25-<30$ n (\%) & $622(37 \%)$ \\
\hline $\mathrm{BMI} \geq 30-<35$ n $(\%)$ & $332(20 \%)$ \\
\hline $\mathrm{BMI} \geq 35 \mathrm{n}(\%)$ & $156(9 \%)$ \\
\hline
\end{tabular}

\section{Comorbidities by BMI Strata}

The number of comorbidities increases with each BMI category, with the highest number in the very

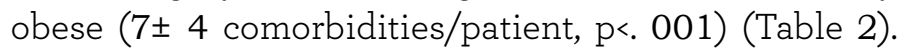
Comorbidities with more than $5 \%$ prevalence per group are displayed in e-Table 1 within the online supplement. 


\section{Table 2. Differences in Demographic, Anthropometric, Symptoms and Physiologic Variables by BMI Categories}

\begin{tabular}{|c|c|c|c|c|c|c|}
\hline & $\mathrm{BMI} \leq 21$ & $21<B M \mid<25$ & $25 \leq B M \mid<30$ & $30 \geq B M \mid<35$ & $\mathrm{BMI} \geq 35$ & p value \\
\hline Group & 1 & 2 & 3 & 4 & 5 & \\
\hline n (females) & $254(37)$ & $295(55)$ & $622(49)$ & $332(33)$ & $156(11)$ & \\
\hline $\operatorname{BMI}\left(\mathrm{kg} / \mathrm{m}^{2}\right)$ & $19.3 \pm 1.7$ & $23.1 \pm 0.8$ & $26.8 \pm 1.4$ & $31.6 \pm 1.4$ & $38.1 \pm 3.7$ & $<0.0001$ \\
\hline Age (years) & $66 \pm 10$ & $67 \pm 10^{5}$ & $67 \pm 9^{5}$ & $66 \pm 9$ & $64 \pm 8$ & 0.0364 \\
\hline $\begin{array}{l}\text { Pack-years (median, } \\
\text { IQR) }\end{array}$ & $69(48-100)$ & $69(45-100)$ & $64(45-100)$ & $70(45-100)$ & $80(45-120)$ & 0.414 \\
\hline Current Smoker (\%) & $51 \%{ }^{2,3,4,5}$ & $33 \%$ & $27 \%$ & $29 \%$ & $27 \%$ & $<0.0001$ \\
\hline SGRQ total score ${ }^{c}$ & $53.5 \pm 20.5^{3}$ & $49.0 \pm 21.6$ & $47.8 \pm 20.8$ & $49.0 \pm 21.8$ & $51.4 \pm 20.8$ & 0.011 \\
\hline \# of Comorbidities & $5 \pm 3$ & $5 \pm 4$ & $6 \pm 4$ & $5 \pm 3$ & $7 \pm 4^{1,2,3,4}$ & $<0.001$ \\
\hline $\mathrm{FEV}_{1} \%$ predicted & $41 \pm 21^{2,3,4,5}$ & $47 \pm 20$ & $51 \pm 20$ & $52 \pm 19^{2,3}$ & $51 \pm 17$ & $<0.0001$ \\
\hline IC/TLC (\%) ${ }^{\mathrm{d}}$ & $23 \pm 9^{2,3,4,5}$ & $27 \pm 9^{3,4,5}$ & $30 \pm 9^{4,5}$ & $33 \pm 12$ & $34 \pm 11$ & $<0.0001$ \\
\hline $\mathrm{DL}_{\mathrm{co}}(\% \text { predicted })^{\mathrm{e}}$ & $47 \pm 21^{2,3,4,5}$ & $56 \pm 23^{1,4,5}$ & $60 \pm 23^{1,4,5}$ & $66 \pm 20$ & $65 \pm 19$ & $<0.0001$ \\
\hline mMRC Score & $2.5 \pm 1.2^{2,3,4,5}$ & $2.0 \pm 1.2$ & $1.9 \pm 1.2$ & $2.0 \pm 1.2$ & $2.2 \pm 1.1^{2,3,4}$ & $<0.05$ \\
\hline $6 \mathrm{MWT}$ (meters) & $325 \pm 155^{2,3,4}$ & $386 \pm 133$ & $389 \pm 134$ & $397 \pm 132$ & $353 \pm 126^{2,3,4}$ & $<0.001$ \\
\hline BODE Score & $5.6 \pm 2.7^{2,3,4,5}$ & $3.6 \pm 2.5$ & $3.3 \pm 2.4$ & $3.2 \pm 2.4$ & $3.5 \pm 2.4$ & $<0.0001$ \\
\hline
\end{tabular}

We assigned a number to each BMI category (second row in the table) as an abbreviated identifier and used the assigned number to indicate in superscript when a significant difference exists between groups. When a significant difference exists, the reference cell is shaded. A grey scale was used, with darker shades indicating lower p-values.

\begin{tabular}{|l|l|l|l|}
\hline $\mathrm{p}$-value & $0.05-0.0049$ & $0.005-0.00049$ & $<0.0005$ \\
\hline
\end{tabular}

\footnotetext{
a Data missing for 31 participants distributed among all 5 categories $(1=252,2=288,3=608,4=327,5=153)$.

$\mathrm{b}$ Data missing for 165 participants distributed among all 5 categories $(1=241,2=266,3=553,4=291,5=143)$.

${ }^{c}$ Data missing for 656 participants distributed among all 5 categories $(1=146,2=188,3=365,4=195,5=109)$.

$\mathrm{d}$ Data missing for 844 participants distributed among all 5 categories $(1=130,2=145,3=302,4=149,5=89)$.

e Data missing for 552 participants distributed among all 5 categories $(1=185,2=196,3=416,4=197,5=113)$
}

We observed significant differences at the extremes of the BMI spectrum: patients with BMI $\leq 21 \mathrm{~kg} / \mathrm{m}^{2}$ had a significantly higher prevalence of abdominal aortic aneurism, substance abuse, osteoporosis, peripheral artery disease and for males, prostate cancer. On the other extreme, obese and very obese participants (BMI $\geq 30 \mathrm{~kg} /$ $\mathrm{m}^{2}$ ) had a higher prevalence of systemic hypertension, hyperlipidemia, sleep apnea, diabetes mellitus, chronic renal failure, congestive heart failure, gout, venous insufficiency, degenerative joint disease, pulmonary hypertension and for males, erectile dysfunction (e-Table 1 and Figure 1 ). Other comorbidities associated with increased risk for mortality in COPD ${ }^{5,19}$ namely atrial fibrillation, pulmonary fibrosis, cancers and gastric/ duodenal ulcer had similar prevalence in the different BMI groups (e-Table 1). 


\section{Figure 1. Comorbidity Prevalence Between BMI Categories}

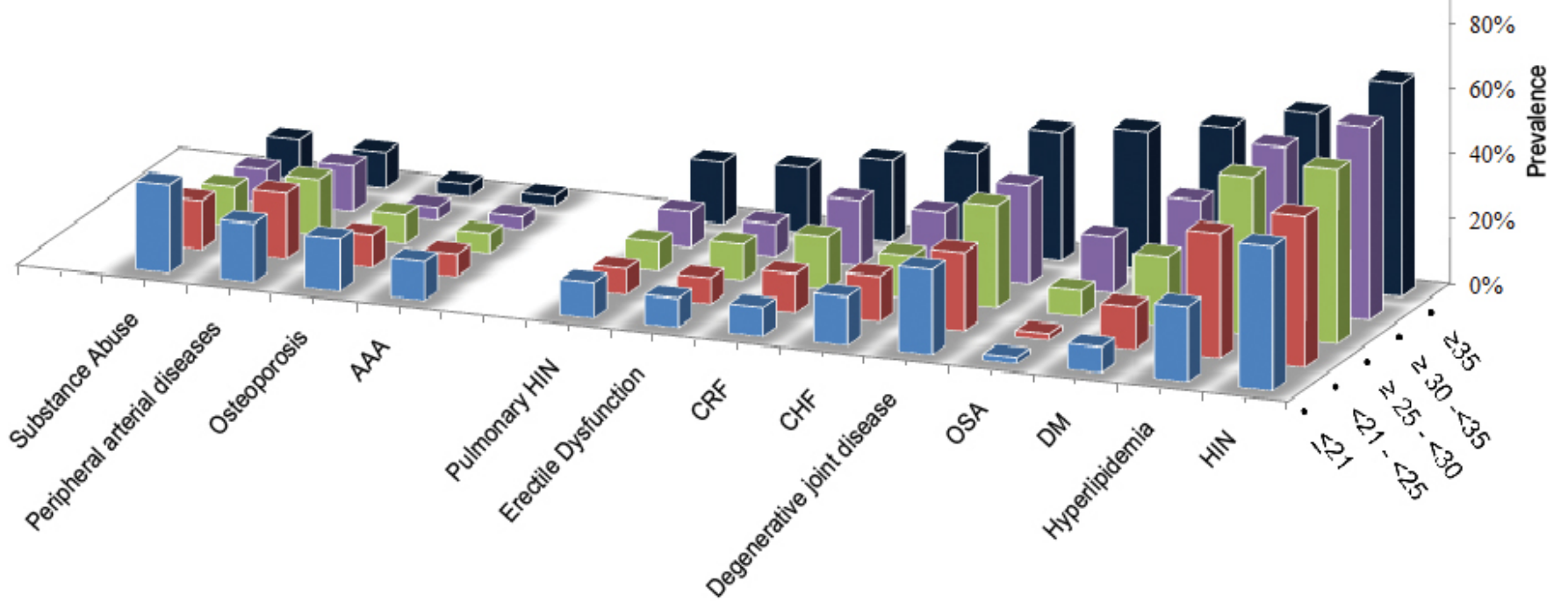

\section{X-axis represents the comorbidity name, Y-axis represents preva
Table 3. Comorbidities Associated with
an Increased Risk of Death for Patients with COPD by BMI Categories Adjusted for Age, Gender, Degree of Obstruction and Smoking Status}

\begin{tabular}{|c|c|c|c|c|}
\hline Comorbidity & $\begin{array}{c}\text { Prevalenc } \\
(\%)\end{array}$ & $\begin{array}{c}\text { Hazard } \\
\text { Ratio }\end{array}$ & $95 \% \mathrm{Cl}$ & $p$ \\
\hline \multicolumn{5}{|l|}{$\mathrm{BMI} \leq 21 \mathrm{~kg} / \mathrm{m}^{2}$} \\
\hline Atrial Fibrillation/Flutter & 14 & 1.63 & $0.99-2.58$ & 0.0504 \\
\hline Coronary Artery Disease & 28 & 1.71 & $1.12-2.60$ & 0.0134 \\
\hline \multicolumn{5}{|l|}{$21<\mathrm{BMI}<25 \mathrm{~kg} / \mathrm{m}^{2}$} \\
\hline Hypertension & 46 & 1.62 & $1.04-2.51$ & 0.0315 \\
\hline Diabetes with Neuropathy & 2 & 4.37 & $1.102-13.35$ & 0.0374 \\
\hline
\end{tabular}

\section{$25 \leq B M I<30 \mathrm{~kg} / \mathrm{m}^{2}$}

\begin{tabular}{lcc|ccc}
\hline Coronary Artery Disease & 29 & 1.38 & $1.01-1.88$ & 0.047 \\
\hline Atrial Fibrillation/Flutter & 12 & 1.52 & $1.04-2.20$ & 0.0324 \\
\hline Pulmonary Hypertension & 9 & 1.61 & $1.08-2.35$ & 0.0204 \\
\hline Pulmonary Fibrosis & 8 & 1.86 & $1.19-2.82$ & 0.0079 \\
\hline Congestive Heart Failure & 14 & 1.94 & $1.32-2.80$ & 0.0009 \\
\hline Lung Cancer & 10 & 2.12 & $1.45-3.02$ & 0.0002 \\
\hline Liver Cirrhosis & 2 & 2.96 & $1.39-5.68$ & 0.0068 \\
\hline
\end{tabular}

\section{$\mathrm{BMI} \geq 30 \mathrm{~kg} / \mathrm{m}^{2}$}

\begin{tabular}{lcc|cc|c}
\hline Diabetes Mellitus & 36 & 1.52 & 1.01 & -2.28 & 0.0429 \\
\hline Pulmonary Hypertension & 11 & 1.82 & 1.10 & -2.93 & 0.0198 \\
\hline Pulmonary Fibrosis & 5 & 1.98 & $1.02-3.57$ & 0.0427 \\
\hline Lung Cancer & 8 & 4.16 & $2.65-6.39$ & $<.0001$ \\
\hline
\end{tabular}

Table 3 shows those comorbidities that impact on survival in each BMI category independent of age and severity of obstruction. While only coronary artery disease and atrial fibrillation influences the $\leq 21 \mathrm{~kg} /$ $\mathrm{m}^{2}$ BMI group, lung cancer, diabetes mellitus with neuropathy, liver cirrhosis, congestive heart failure, pulmonary hypertension and pulmonary fibrosis are associated with increased risk of death in those with a $\mathrm{BMI} \geq 25 \mathrm{~kg} / \mathrm{m}^{2}$.

\section{Clinical Variables by BMI Categories}

Comparison of demographic, symptom and physiological variables by BMI categories are shown in Table 2 and e-Figure 1 (in the online supplement). The very obese (BMI $\geq 35 \mathrm{~kg} / \mathrm{m}^{2}$ ) were younger compared to the other categories, and all groups had similar cumulative cigarette exposure (pack/years), yet the underweight group had the highest percentage of current smokers.

Comparing from the lowest to the highest BMIs, an ascending linear relationship is seen in $\mathrm{FEV}_{1}$ \% predicted and the number of comorbidities, while the BODE score has an inverse (worse) linear relationship. A "U" shaped pattern is seen for mMRC and the SGRQ scores, and an inverse "U" shape for the 6MWD (e-Figure 1 within the online supplement).

\section{BMI, Survival, and Cause of Death}

The median follow-up was 51 months [IQR 27-77] and during this period we observed 671 deaths (40.5\%). The crude all cause mortality rate was $60 \%, 43 \%$ $37 \% 36 \%$ and $28 \%$ from the lowest to highest BMI 
groups respectively ( $p<.0001)$. Specific causes of death (respiratory, cancer, cardiovascular, other and unknown causes) were proportional between groups except for respiratory cause of death which was significantly higher in the BMI $\leq 21$ ( $67 \%$ of all deaths in this group) and BMI $\geq 35$ ( $52 \%$ of all deaths in this group) compared to $46 \%$ and $32 \%$ in the other groups ( $p=0.0016)$ (e-Figure 3 within the online supplement).

The Kaplan-Meier curves are presented in e-Figure 2, the median [95\% confidence interval (CI)] survival times in months from the lowest to highest BMI categories

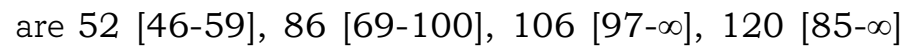
and $114[103-\infty]$ respectively, and the differences are significant by the log-rank test ( $\mathrm{p}<.0001)$.

The mortality risk expressed as risk ratio adjusted for age and degree of obstruction ( $\mathrm{FEV}_{1} \%$ of predicted) using the group of BMI between 21 and $25 \mathrm{~kg} / \mathrm{m}^{2}$ as the comparator are 1.57 (CI 1.24- 1.99, $\mathrm{p}=0.0002$ ) for $\mathrm{BMI} \leq 21 \mathrm{~kg} / \mathrm{m}^{2}, 0.77$ (CI 0.62- 0.96, p 0.02) for BMI $\geq 25$ and $<30 \mathrm{~kg} / \mathrm{m}^{2}, 0.91$ (CI $0.70-1.17, \mathrm{p}=0.45$ ) for $\mathrm{BMI} \geq 30$ and $<35 \mathrm{~kg} / \mathrm{m}^{2}$ and 0.65 (CI $0.46-0.91$, p 0.01) for BMI $\geq 35 \mathrm{~kg} / \mathrm{m}^{2}$ (Figure 2 Panel A). Risk ratios for cause-specific mortality are shown in Figure 2 Panel B (respiratory causes of death), Panel C (cancer cause of death) and Panel D (cardiac cause of death) demonstrating that respiratory cause of death is the main driver of increased risk for the lowest BMI group.

\section{Discussion}

This multi-center observational study of COPD patients attending outpatient clinics with a median follow up of 51 months had several findings. First, comorbidities clustered differently across BMI categories and specific comorbidities that impact independently on mortality are also different in the BMI groups. Second, the degree of obstruction, diffusing capacity and hyperinflation are worse at the lowest BMI group and follow an ascending linear pattern as BMI increases while quality of life, dyspnea perception and walked distance in 6 minutes are worse in both extremes of the BMI spectrum compared to patients in normal range of BMI, likely representing different mechanisms in their genesis. Third, we extend on previous reports by including a large number of patients with BMIs above $35 \mathrm{~kg} / \mathrm{m}^{2}$ (very obese COPD) showing that these patients had the lowest risk for short term (all-cause) death compared to underweight and normal weight patients.

Taken together these results provide evidence of an

\section{Figure 2. Overall and Cause-specific Mortality Risk Ratio Between BMI Categories}
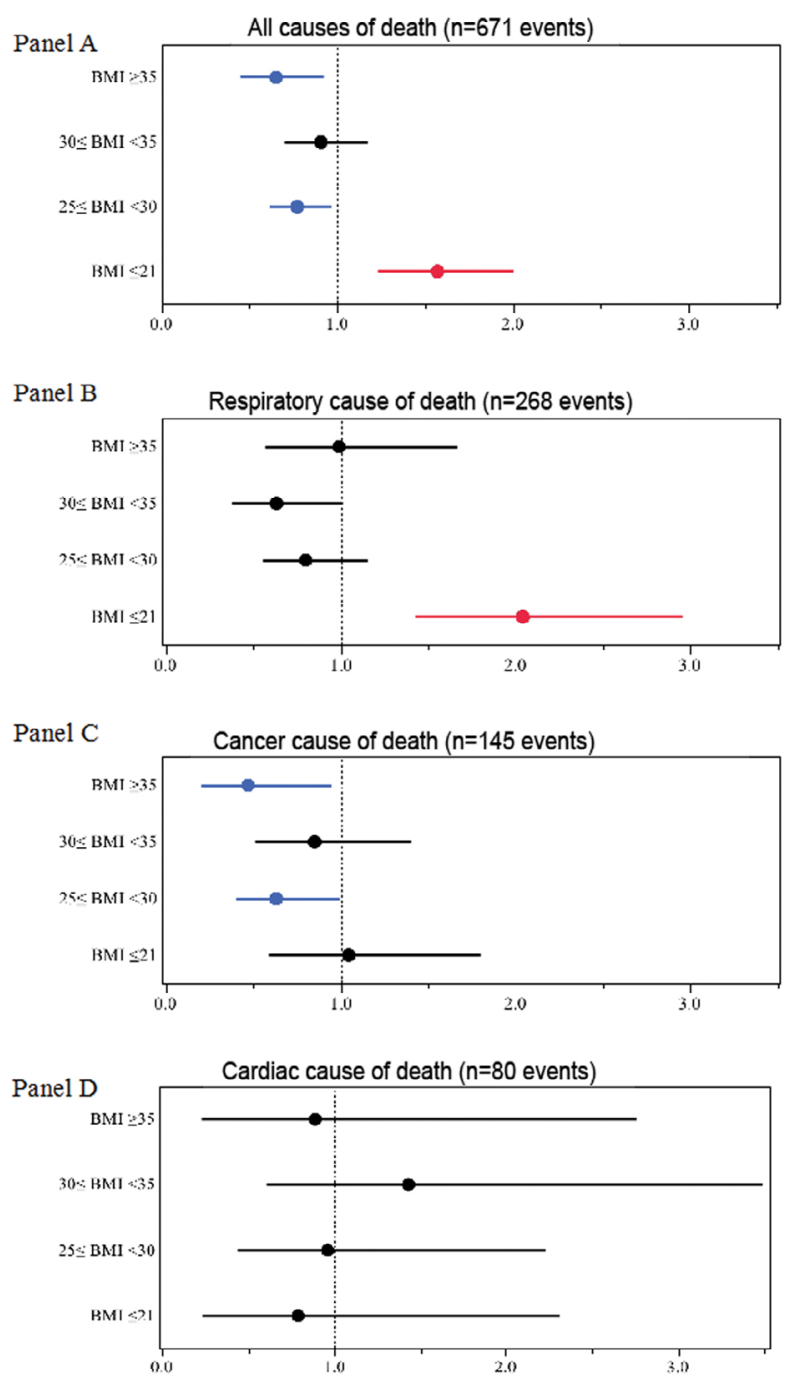

Forrest plot comparing overall and cause-specific mortality risk ratio between $B M I$ categories using $B M I>21$ and $<25 \mathrm{~kg} / \mathrm{m}^{2}$ as the comparator group and the effect of comorbidities.

association between BMI, the clinical expression of comorbidity clusters and outcomes in patients with COPD.

\section{BMI, Comorbidity and Clinical Expression of COPD}

The finding that comorbidities cluster differently in COPD patients when categorized by BMI is informative as epidemiologic and association studies usually describe the impact of individual or limited number of comorbidities in smaller COPD cohorts. ${ }^{12,20-26}$ The lowest BMI group had more airflow obstruction, hyperinflation, osteoporosis, abdominal aortic aneurism, 
peripheral vascular disease and history of substance abuse, a cluster of findings that suggest a possible linkage through lung tissue, adipose tissue and mesenchymal stem cell (dys)function. ${ }^{27,28}$ The latter are capable of differentiating into a number of phenotypes, which include cells capable of fabricating bone, muscle, marrow, adipocytes, and connective tissue. $^{27}$ On the other hand the very obese individuals had less airflow obstruction, little osteoporosis and exhibited a cluster of known comorbidities and risk factors for cardiovascular diseases with increased systemic inflammation. 1,13,29-31 Perhaps the adipose tissue plays a modulating role in disease expression in the 2 groups as the disease begins and progresses, a hypothesis that we believe deserves attention. ${ }^{14-16,28}$

The relationship between specific comorbidities, BMI and the risk of death is depicted in Table 3. Whereas very few comorbidities were statistically associated with increased risk of death in the underweight, many more were associated with increased risk for death in patients in the higher BMI categories, suggesting that comorbidities play an important role in determining the final, but not necessarily the speed, of the outcome.

The very obese and the cachectic groups had worse health status and lower functional capacity than patients with more normal BMI. A simple unifying explanation is difficult to find, so it is tempting to speculate that the reasons for the observation may be due to different pathophysiologic mechanisms. Whereas in the cachectic patient air trapping and hyperinflation may contribute significantly to impaired function of the respiratory muscles, the very obese patient may be hindered by the effects of the weight on ventilatory and bodily functions. ${ }^{1,9,32}$ In addition, patients in the cachectic group were more likely to be current smokers, which may help explain some of the differences.

\section{Respiratory Cachexia or Obesity Paradox?}

It is well established that low BMI increases the risk for mortality in patients with COPD, ${ }^{6,33}$ however, data for the very obese group of COPD patients (BMI above $35 \mathrm{~kg} / \mathrm{m}^{2}$ ) is scarce as most large studies group the obese in a single category (BMI $\geq 30 \mathrm{~kg} / \mathrm{m}^{2}$ ), probably because there are few very obese patients in those series. ${ }^{7,8,11,34-36}$ Our study includes 156 individuals with morbid obesity and expands on previous observations that this group of patients has the lowest overall mortality (obesity paradox), despite a higher number of comorbidities. Interestingly, those who died were mainly from respiratory causes, an observation already described by Jordan et al in the National Health and Nutrition Examination Survey (NHANES III) ${ }^{9,37}$ and for which the reason remains unexplained, but should be explored as morbid obesity becomes a frequently observed phenotype in the COPD population.

We observed a cluster of characteristics in the undernourished subgroup associated with poor short-term prognosis and higher rates of respiratory death, including worse obstruction, hyperinflation, and dyspnea perception, lower walking distance and therefore a higher BODE index. This could provide a possible reason for the paradox, as BMI stratification clusters in both extremes of the spectrum of the shortterm vs. longer-term risk factors. Our observation supports the hypothesis of time differential where obese and very obese COPD individuals may experience a slower process with potential clinical intervention (long term killer, short term protection) than the rapid effect of cachexia-malnutrition, a short term killer for which there is little success with known interventions. 10,38-40

In contrast, the higher number and the nature of comorbidities seen in obese vs. the low BMI individuals argues against the presence of a bias due to reverse causation. ${ }^{1,11,41,42}$ Our data indicates that the cachectic group had higher overall and respiratory cause of death, with less prevalence of comorbidities known to cause cachexia-malnutrition such as chronic renal failure or congestive heart failure. Similarly, our findings contend against survival selection bias because at baseline we excluded individuals with advanced cardiovascular diseases, active cancer or with any illness other than COPD likely to result in death in less than a year. Similarly, the difference was not due to age differential as we adjusted the Cox models for age and still obtained similar results.

\section{Study Limitations}

There are several limitations in our study. First, our conclusions are only applicable to predominantly male individuals with COPD recruited from pulmonary specialty clinics while seeking medical assistance. However, the similarity in their demographic and physiological characteristics to COPD patients attending primary care clinics ${ }^{17,43}$ and the large number of patients included and followed over a long period of time suggests that our findings could be extended to the clinician experience. Second, because we used BMI at 
study entry for our analysis, it could be argued that our findings reflect reverse causation, ${ }^{18,34,41}$ nevertheless we excluded patients with severe comorbidities and those at high risk of death, avoiding the inclusion of individuals with rapid weight loss, thus decreasing the reverse causation bias. Third, BMI is a marker of general adiposity and we failed to provide either the fat free mass or waist circumference measurements, both known to provide more information than BMI alone. ${ }^{5,11}$ However, BMI is clinically easy to measure, is recommended by the NHLBI and is associated with poor outcome in COPD. Fourth, an unintended source of bias could be introduced if clinicians screened for specific diseases in patients with different BMIs, such as cardiovascular diseases in obese individuals. Nevertheless, our results are aligned with the results of other studies using different disease ascertainment and analysis methods, supporting little influence from this potential bias. $7,8,26$ Finally it can be argued that the Cox model was underpowered for the BMI category $\leq 21 \mathrm{~kg} / \mathrm{m}^{2} \quad(\mathrm{n}=254)$ resulting in a small number of comorbidities affecting mortality, nonetheless we used 24 comorbidities in our model (1 predictor: 10 participants). In addition, this group had the largest number of events (death) supporting the validity of our results.

In conclusion, different BMI categories are associated with distinct clinical expression and the number and type of comorbid diseases seen in patients with COPD. COPD patients categorized by BMI groups differ in survival and cause of death, suggesting that adipose tissue may be modulating the response to the irritants causative of COPD. In addition, our results expand on the so called obesity paradox phenomena, by showing that patients with COPD manifest different physiological, functional and perceptive expressions according to their BMI. Taken together, these results support the use of BMI as a stratifying variable to grade COPD.

Acknowledgments: All listed authors attest that they: 1) made substantial contributions to the conception and design, acquisition of data, or analysis and interpretation of data; 2) drafted the article or revised it critically for important intellectual content; and 3) provided final approval of the version to be submitted for revision.

Declaration of Interest: There is no direct or perceived conflict of interest in either the support, analysis and content of the manuscript by any of the authors. The authors of the manuscript are solely responsible for the data collection, analysis and crafting of the manuscript. There is no direct or indirect relationship with tobacco industry. 


\section{References}

1. Celli BR, Cote CG, Marin JM, et al. The body-mass index, airflow obstruction, dyspnea, and exercise capacity index in chronic obstructive pulmonary disease. NEngl J Med.2004;350(10):10051012. doi: http://dx.doi.org/10.1056/NEJMoa021322

2. Vestbo J, Hurd SS, Agustí AG, et al. Global strategy for the diagnosis, management, and prevention of chronic obstructive pulmonary disease. Am J Respir Crit Care Med. 2013; 187(4):347365. doi: http://dx.doi.org/10.1164/rccm.201204-0596PP

3. Casanova C, Aguirre-Jaime A, de Torres J, et al. Longitudinal assessment in COPD patients: multidimensional variability and outcomes. Eur Respir J. 2014;44:324-331.

4. Marin JM, Alfageme I, Almagro P, et al. Multicomponent indices to predict survival in COPD: the COCOMICS study. Eur Respir J. 2013; 42(2):323-332. doi: http://dx.doi. org/10.1183/09031936.00121012

5. Pischon T, Boeing H, Hoffmann $\mathrm{K}$, et al. General and abdominal adiposity and risk of death in Europe. $N$ Engl $J$ Med. 2008;359(20):2105-2120. doi: http://dx.doi.org/10.1056/ NEJMoa0801891

6. National Institutes of Health, National Heart Lung and Blood Institute Obesity Education Initiative Expert Panel on the Identification, Evaluation, and Treatment of Obesity in Adults. Executive summary of the clinical guidelines on the identification, evaluation, and treatment of overweight and obesity in adults. Arch Intern Med. 1998;158(17):18551867. doi:10.1001/archinte.158.17.1855. doi: http://dx.doi. org/10.1001/archinte.158.17.1855

7. Garcia-Aymerich J, Gómez FP, et al; for PAC-COPD Study Group. Identification and prospective validation of clinically relevant chronic obstructive pulmonary disease (COPD) subtypes. Thorax. 2011;66(5):430-437. doi: http://dx.doi. org/10.1136/thx.2010.154484

8. Burgel PR, Paillasseur JL, Caillaud D, et al; for the Initiatives BPCO Scientific Committee. Clinical COPD phenotypes: a novel approach using principal component and cluster analyses. Eur Respir J. 2010;36(3):531-539. doi: http://dx.doi. org/10.1183/09031936.00175109

9. Franssen FME, O'Donnell DE, Goossens GH, Blaak EE, Schols AMWJ. Obesity and the lung: 5 - Obesity and COPD. Thorax. 2008;63(12):1110-1117. doi: http://dx.doi.org/10.1136/ thx.2007.086827

10. Agustí A, Edwards LD, Rennard SI, et al; Evaluation of COPD Longitudinally to Identify Predictive Surrogate Endpoints (ECLIPSE) investigators. Persistent systemic inflammation is associated with poor clinical outcomes in COPD: a novel phenotype. PLoS ONE. 2012;7(5):e37483. doi: http://dx.doi. org/10.1371/journal.pone.0037483

11. Vestbo J, Prescott E, Almdal T, et al. Body mass, fat free body mass and prognosis in COPD patients from a random population sample: findings from the Copenhagen City heart study. Am J Respir Crit Care Med. 2005;173(1):79-83. doi: http:// dx.doi.org/10.1164/rccm.200506-9690C
12. Celli BR, MacNee W; ATS/ERS Task Force. Standards for the diagnosis and treatment of patients with COPD: a summary of the ATS/ERS position paper. Eur Respir J. 2004; 23(6)932-946. doi: http://dx.doi.org/10.1183/09031936.04.00014304

13. Schols AM, Slangen J, Volovics L, Wouters EF. Weight loss is a reversible factor in the prognosis of chronic obstructive pulmonary disease. Am J Respir Crit Care Med. 1998;157(6 Pt 1):1791-1797. doi: http://dx.doi.org/10.1164/ ajrccm.157.6.9705017

14. Miller MR, Crapo R, Hankinson J, et al; ATS/ERS Task Force. General considerations for lung function testing. Eur Respir J. 2005; 26(1):153-161. doi: http://dx.doi.org/10.1183/09031936.05.00034505

15. Brooks D, Solway S, Gibbons WJ. ATS statement on six-minute walk test. Am J Respir Crit Care Med. 2003;167(9):1287. doi: http://dx.doi.org/10.1164/ajrccm.167.9.950

16. ATS Committee on Proficiency Standards for Clinical Pulmonary Function Laboratories. ATS statement: guidelines for the sixminute walk test. Am J Respir Crit Care Med. 2002;166(1):111117. doi: http://dx.doi.org/10.1164/ajrccm.166.1.at1102

17. Charlson ME, Pompei P, Ales KL, MacKenzie CR. A new method of classifying prognostic comorbidity in longitudinal studies: development and validation. J Chronic Dis. 1987;40(5):373-383. doi: http://dx.doi.org/10.1016/0021-9681(87)90171-8

18. McGarvey LP, John M, Anderson JA, Zvarich M, Wise RA. Ascertainment of cause-specific mortality in COPD: operations of the TORCH Clinical Endpoint Committee. Thorax. 2007;62(5):411-415. doi: http://dx.doi.org/10.1136/ thx.2006.072348

19. Divo MJ, Cote C, de Torres JP, et al; BODE Collaborative Group. Comorbidities and risk of mortality in patients with chronic obstructive pulmonary disease. Am J Respir Crit Care Med. 2012;186(2):155-161. doi: http://dx.doi.org/10.1164/ rccm.201201-0034OC

20. Meijer CA, Kokje VBC, van Tongeren RBM, et al. An association between chronic obstructive pulmonary disease and abdominal aortic aneurysm beyond smoking: results from a case-control study. Eur J Vasc Endovasc Surg. 2012;44(2):153-157. doi: http:// dx.doi.org/10.1016/j.ejvs.2012.05.016

21. Pecci R, La Fuente Aguado De J, Rivo ABS, Conde PS, Abelaira MC. Peripheral arterial disease in patients with chronic obstructive pulmonary disease. Int Angiol. 2012;31(5):444 453.

22. Blum A, Simsolo C, Sirchan R, Haiek S. Obesity paradox in chronic obstructive pulmonary disease. Isr Med Assoc J. 2011;13(11):672-675.

23. Lehouck A, Boonen S, Decramer M, Janssens W. COPD, bone metabolism, and osteoporosis. Chest. 2011;139(3):648-657. doi: http://dx.doi.org/10.1378/chest.10-1427

24. Minas M, Kostikas K, Papaioannou AI, et al. The association of metabolic syndrome with adipose tissue hormones and insulin resistance in patients with COPD without co-morbidities. COPD. 2011;8(6):414 420. doi: http://dx.doi.org/10.3109/15412 555.2011 .619600

25. Young RP, Hopkins RJ, Christmas T, Black PN, Metcalf P, Gamble GD. COPD prevalence is increased in lung cancer, independent of age, sex and smoking history. Eur Respir J. 2009;34(2):380386. doi: http://dx.doi.org/10.1183/09031936.00144208 
26. Vanfleteren LEGW, Spruit MA, Groenen M, et al. Clusters of comorbidities based on validated objective measurements and systemic inflammation in patients with chronic obstructive pulmonary disease. Am J Respir Crit Care Med. 2013;187(7):728735. doi: http://dx.doi.org/10.1164/rccm.201209-1665OC

27. Bonfield TL, Caplan AI. Adult mesenchymal stem cells: an innovative therapeutic for lung diseases. Discov Med. 2010;9(47):337-345.

28. Agustí A, Barberà JA, Wouters EFM, Peinado VI, Jeffery PK. Lungs, bone marrow, and adipose tissue. A network approach to the pathobiology of chronic obstructive pulmonary disease. Am J Respir Crit Care Med. 2013;188(12):1396-1406. doi: http:// dx.doi.org/10.1164/rccm.201308-1404PP

29. Kern E. Metabolic syndrome and systemic inflammation in COPD. COPD. 2011;8(6):395-396. doi: http://dx.doi.org/10.3109 / 15412555.2011 .636554

30. D'Agostino RB, Parise H, Sullivan L, Meigs JB. Metabolic syndrome as a precursor of cardiovascular disease and type 2 diabetes mellitus. Circulation. 2005;112(20):3066-3372. doi: http://dx.doi.org/10.1161/CIRCULATIONAHA.105.539528

31. Tiengo A, Fadini GP, Avogaro A. The metabolic syndrome, diabetes and lung dysfunction. Diabetes Metab J. 2008;34(5):447454. doi: http://dx.doi.org/10.1016/j.diabet.2008.08.001

32. Vozoris NT, O’Donnell DE. Prevalence, risk factors, activity limitation and health care utilization of an obese, populationbased sample with chronic obstructive pulmonary disease. Can Respir J. 2012;19(3):e18-24.

33. Cao C, Wang R, Wang J, Bunjhoo H, Xu Y, Xiong W. Body mass index and mortality in chronic obstructive pulmonary disease: a meta-analysis. PLoS ONE. 2012;7(8):e43892. doi: http://dx.doi. org/10.1371/journal.pone.0043892

34. Prescott E, Almdal T, Mikkelsen KL, Tofteng CL, Vestbo J, Lange P. Prognostic value of weight change in chronic obstructive pulmonary disease: results from the Copenhagen City Heart Study. Eur Respir J. 2002;20(3):539-544.

doi: http://dx.doi.org/10.1183/09031936.02.00532002

35. Chailleux E, Laaban J-P, Veale D. Prognostic value of nutritional depletion in patients with COPD treated by longterm oxygen therapy data from the ANTADIR Observatory. Chest. 2003;123(5):1460-1466. doi: http://dx.doi.org/10.1378/ chest.123.5.1460

36. Hansen EF, Phanareth K, Laursen LC, Kok-Jensen A, Dirksen A. Reversible and irreversible airflow obstruction as predictor of overall mortality in asthma and chronic obstructive pulmonary disease. Am J Respir Crit Care Med. 1999;159(4):1267-1271. doi: http://dx.doi.org/10.1164/ajrccm.159.4.9807121

37. Jordan JG Jr, Mann JR. Obesity and mortality in persons with obstructive lung disease using data from the NHANES III. South Med J. 2010;103(4):323-330. doi: http://dx.doi.org/10.1097/ SMJ.0b013e3181d394b4
38. Schols AMWJ. Nutritional and metabolic modulation in chronic obstructive pulmonary disease management. Eur Respir J. 2003;22(Supp 46):81s-86s. doi: http://dx.doi.org/10.1183/09031 936.03.00004611

39. Wagner PD. Possible mechanisms underlying the development of cachexia in COPD. Eur Respir J. 2008;31(3):492-501. doi: http://dx.doi.org/10.1183/09031936.00074807

40. Kramer CK, Zinman B, Retnakaran R. Are metabolically healthy overweight and obesity benign conditions? Ann Intern Med. 2013;159(11):758. doi: http://dx.doi.org/10.7326/0003-4819-15911-201312030-00008

41. Flegal KM, Graubard BI, Williamson DF, Cooper RS. Reverse causation and illness-related weight loss in observational studies of body weight and mortality. Am J Epidemiol. 2010;173(1):1-9. doi: http://dx.doi.org/10.1093/aje/kwq341

42. Kalantar-Zadeh K, Horwich TB, Oreopoulos A, et al. Risk factor paradox in wasting diseases. Curr Opin Clin Nutr Metab Care. 2007;10(4):433-442. doi: http://dx.doi.org/10.1097/ MCO.0b013e3281a30594

43. van der Molen T. Co-morbidities of COPD in primary care: frequency, relation to COPD, and treatment consequences. Prim Care Respir J. 2010;19(4):326. doi: http://dx.doi.org/10.4104/ pcrj.2010.00053 